\title{
Stressful life events, hopelessness, and coping strategies among impulsive suicide attempters
}

\author{
Shivanand Kattimani, Siddharth Sarkar, Ravi Philip Rajkumar, Vikas Menon \\ Department of Psychiatry, JIPMER, Puducherry, India
}

\begin{abstract}
Background: Suicides are among the most important causes of death in the economically productive population. Characteristics of impulsive and nonimpulsive suicide attempters may differ which would have a bearing on planning preventive measures. Aims: This study aimed to characterize the clinical and psychological profile of impulsive and nonimpulsive suicide attempters. Settings and Design: This retrospective comprehensive chart-based study was conducted at a tertiary care hospital in South India. Methods: The study utilized records of patients over a period of 3 years. An attempt was considered impulsive if the time between suicidal idea and the attempt was $<30 \mathrm{~min}$. Stressful life events were assessed using presumptive stressful life events scale; hopelessness was evaluated using Beck Hopelessness Scale (BHS) and coping was measured using Coping Strategies Inventory Short Form. Statistical Analysis Used: Impulsive and nonimpulsive suicide attempters were compared using appropriate inferential statistical tests. Results: Of 316 patients, 151 were classified as having an impulsive suicidal attempt (47.8\% of the sample). The impulsive and nonimpulsive suicide attempters did not differ on demographic characteristics. Use of natural plant products was more common in impulsive attempters $(27.2 \%$ vs. $12.7 \%)$, while physical methods like hanging was less common (0.7\% vs. 7.3\%). Those with an impulsive attempt were more likely to have a recent contact with a health professional (24.5\% vs. $4.5 \%$ ). Impulsive suicide attempters had higher scores on BHS (Mann-Whitney $U=7680.5, P<0.001$ ), and had recollected greater number of stressors. Conclusion: Impulsive suicide attempters differ from nonimpulsive suicide attempters in clinical features like methods of attempt, presence of hopelessness, and stressors.
\end{abstract}

Key words: Coping, hopelessness, impulsive, stress, suicide attempt

\section{Introduction}

Suicide is a complex human behavior, which has biological, psychological, and social determinants. ${ }^{[1]}$ It is among the leading causes of premature death among the economically productive population..$^{[2]}$ Suicidal behaviors can be impulsive at times, resulting from frustration, anger or as a means of manipulation. ${ }^{[3]}$ Impulsive suicidal attempts can be considered as those that occur without much forethought and may not be associated with a clear intention of death, but at the same time can be potentially fatal. Impulsive

\begin{tabular}{|l|l|}
\hline \multicolumn{2}{|c|}{ Access this article online } \\
\hline Quick Response Code: & Website: \\
\hline & www.ruralneuropractice.com \\
\cline { 2 - 2 } & \\
\hline & \\
\hline
\end{tabular}

suicide has been defined differently by different researchers: Based on the time interval between suicidal thought and attempt, ${ }^{[4]}$ and based on a particular item on suicide intent scale. ${ }^{[5,6]}$ As these patients with impulsive suicide attempt appear to have a distinct clinical profile, with specific implications for prevention and management, research aiming to delineate this profile is important. ${ }^{[7]}$

Stressful life events have often been associated with impulsive suicide attempts. ${ }^{[4,8]}$ Effective coping may act as a deterrent from suicidal behaviors in certain individuals by helping them to deal well with stress in life. On the other hand, certain types of coping like avoidance may predispose a person to suicidal behaviors. ${ }^{[9]}$ Apart from coping, interplay of other factors such as hopelessness and impulsivity may also contribute toward suicidal behaviors. ${ }^{[10,11]}$ Understanding how these factors influence the suicidal behaviors may help devise strategies to counteract them.

Address for correspondence: Dr. Shivanand Kattimani, Department of Psychiatry, JIPMER, Dhanvantary Nagar, Puducherry - 605006 , India. E-mail: drshivanand@gmail.com 
It has been suggested that suicidal attempts may be more commonly impulsive in the developing countries as compared to being mood disorder related in the developed countries. ${ }^{[12]}$ Indian studies have found lower rates of depressive illnesses in those attempting suicide, a finding which is at variance with Western studies. ${ }^{[13]}$ In this geographical region, suicides are often more closely related to adverse life events than to psychiatric diagnoses. ${ }^{[1,15]}$ Little is known about the profile of individuals who make impulsive suicide attempts in the region, compared to those who make planned attempts. Hence, this retrospective chart review was carried out to delineate the clinical and psychological profile of impulsive suicide attempters who were treated in a hospital setting in South India.

\section{Methods}

\section{Setting}

The present retrospective chart review-based study was conducted in the Department of Psychiatry of a tertiary care government hospital in South India. The hospital is located in a semi-urban area and provides highly subsidized treatment to patients. The Department of Psychiatry runs a specialized crisis intervention clinic (CIC) which provides psychiatric evaluation and care for patients who have medically stabilized in the hospital after attempted suicide. The CIC uses the definition of "suicide attempt" as "a self-inflicted, potentially injurious behavior with a nonfatal outcome for which there is evidence either explicit or implicit of intent to die." ${ }^{[16]}$ The clinic is manned by a consultant, a resident, and a social worker. Patients undergo a detailed assessment using a structured proforma designed for the clinic, and a management plan is drawn up. The therapeutic strategies include outpatient or inpatient based pharmacotherapy and counseling.

\section{Procedure}

We performed a retrospective chart review of all consecutive subjects who were assessed in CIC over a 3-year period from July 1, 2010 to June 30, 2013. For each of the patients registered in the CIC during the study period, detailed assessments were carried out using a semi-structured questionnaire. The demographic and clinical data were recorded, along with hopelessness measured by Beck's Hopelessness Scale (BHS), ${ }^{[17]}$ coping evaluated using the Coping Strategies Inventory Short Form ${ }^{[18]}$ and stressful life events in the past 1-year using the presumptive stressful life events scale checklist (PSLES). ${ }^{[19]}$ The information collected from the patients and their family members was recorded into the proforma under supervision of the consultant, and clinical diagnoses were made as per International
Classification of Diseases $10 \cdot{ }^{[20]}$ For the purposes of this study, an impulsive suicidal attempt was operationally defined as one where the time between the occurrence of suicidal idea and the attempt was $<30 \mathrm{~min}$. Previous researchers have also used time-based criteria for defining impulsive suicide attempts. ${ }^{[4,21-23]}$

\section{Instruments}

Beck Hopelessness Scale: This 20 item scale developed by Beck et al. measures hopelessness. ${ }^{[17]}$ BHS includes 9 positively framed and 11 negatively framed statements about one's future. The subject has to read the statements and respond true/false as it applies to him or her. The scale is designed to measure three major aspects of hopelessness, that is, feelings about the future, loss of motivation, and expectations. The internal reliability of the scale has been found to be high. The scale has been validated for age 17-80 years and has been widely used in suicide literature. In present study, subjects were assessed for the presence of hopelessness during their visit in the CIC. Total score ranges from 0 to 20; higher scores suggest a higher level of hopelessness.

Coping Strategies Inventory Short Form: This brief 16 item scale was derived from the 78-item Coping Strategies Inventory. ${ }^{[18,24]}$ The items are rated on a 5 item Likert scale from 1 to 5 rated as never, seldom, sometimes, often, and almost always. The different forms of self-reported coping responses that are generally used when faced with difficult situations are evaluated through this scale. Coping responses are classified into emotion-focused and problem-focused, which are further sub-classified as either engagement type or disengagement type of strategy.

Presumptive stressful life events scale checklist: This scale has been developed and validated in the Indian population and measures stressful life events for an individual. This 51 item yes-no self-rated scale takes about 5 min to complete. It is based on the Holmes and Rahe scale ${ }^{[25]}$ and includes both positive and negative life events, each having different scores. In the present study, the PSLES was used to assess the number of stressful life events in the past 1-year period prior to the current suicide attempt.

\section{Statistical analysis}

Analysis was carried out using SPSS Statistics for Windows, Version 17.0. Chicago: SPSS Inc. Descriptive statistics including means, standard deviations, frequencies, and percentages were used to summarize the demographic and clinical data. Inferential statistics in the form of student's $t$-test and Chi-square test were used to compare the impulsive suicide attempt group 
with the nonimpulsive group. Binary logistic regression analysis was conducted to identify the independent predictors of impulsive attempt status. Missing value imputation was not conducted. A $P<0.05$ was considered significant in the present study. No statistical correction was considered for multiple statistical tests done.

\section{Results}

During the study period, 347 patients were referred to the CIC. Of them, 31 were not included in analysis for the following reasons: Suicidal attempt could not be established as per predefined criteria in 13 patients, ${ }^{[16]}$ and time duration between suicidal idea and attempt was not recollected in 18 patients. The remaining 316 patients ( $91.1 \%$ of the sample) were included in the analysis. Of them, 151 were classified as impulsive suicide attempters (47.8\% of the sample). The demographic characteristics of the patients with impulsive and nonimpulsive suicidal attempts are shown in Table 1. The impulsive and nonimpulsive groups did not differ significantly in terms of age, gender or other demographic characteristics.

The clinical characteristics of both the groups are depicted in Table 2. Use of pesticides was the most common method of suicidal attempt in both the groups. Use of natural plant products was significantly more common in the impulsive suicidal attempt group ( $27.2 \%$ vs. $12.7 \%)$

Table 1: Demographic and clinical comparison between two groups

\begin{tabular}{|c|c|c|c|}
\hline & $\begin{array}{l}\text { Impulsive } \\
\text { suicide } \\
\text { attempts } \\
(n=151)\end{array}$ & $\begin{array}{l}\text { Non-impulsive } \\
\text { suicide } \\
\text { attempts } \\
(n=165)\end{array}$ & $\begin{array}{l}\chi^{2} \text { or students' } \\
t \text { (significance) }\end{array}$ \\
\hline Age & $27.9( \pm 10.5)$ & $26.6( \pm 9.6)$ & $t=1.160(0.247)$ \\
\hline \multicolumn{4}{|l|}{ Gender (\%) } \\
\hline Male & $82(54.3)$ & $86(52.1)$ & \multirow[t]{2}{*}{$\chi^{2}=0.151(0.698)$} \\
\hline Female & $69(45.7)$ & 79 (47.9) & \\
\hline \multicolumn{4}{|l|}{ Marital status (\%) } \\
\hline Married & $76(50.3)$ & $87(52.7)$ & \multirow[t]{2}{*}{$\chi^{2}=0.181(0.671)$} \\
\hline Not married & $75(49.7)$ & $78(47.3)$ & \\
\hline $\begin{array}{l}\text { Completed years } \\
\text { of education (\%) }\end{array}$ & $8.7( \pm 4.3)$ & $8.8( \pm 4.6)$ & $t=0.058(0.954)$ \\
\hline \multicolumn{4}{|l|}{ Residence } \\
\hline Rural & 137 (91.3) & 154 (94.5) & \multirow[t]{2}{*}{$\chi^{2}=1.183(0.277)$} \\
\hline Urban & $13(8.7)$ & $9(5.5)$ & \\
\hline \multicolumn{4}{|l|}{ Family type (\%) } \\
\hline Nuclear & 99 (67.3) & $110(68.8)$ & \multirow[t]{2}{*}{$\chi^{2}=0.069(0.793)$} \\
\hline Others & $48(32.7)$ & $50(31.2)$ & \\
\hline \multicolumn{4}{|l|}{ Employment (\%) } \\
\hline Employed & $85(57.4)$ & $80(48.8)$ & \multirow[t]{2}{*}{$\chi^{2}=2.337(0.126)$} \\
\hline $\begin{array}{l}\text { Not currently } \\
\text { employed }\end{array}$ & $63(42.6)$ & $84(51.2)$ & \\
\hline
\end{tabular}

while physical methods were less common $(0.7 \%$ vs. 7.3\%). Attempts made under the influence of alcohol were roughly similar in both the groups. Love-related issues were more common reasons behind impulsive suicide attempts $(15.9 \%$ vs. $3.6 \%)$ than nonimpulsive attempts. Those with an impulsive attempt were more likely to contact a health professional in the 3 months prior to the attempt ( $24.5 \%$ vs. $4.5 \%)$. There were no significant differences in the rates of current psychiatric disorder.

The measures of hopelessness, coping, and life stressors are depicted in Table 3. Beck Hopelessness Score was worse in the impulsive suicide attempt group (MannWhitney $\mathrm{U}=7680.5, P<0.001)$. Problem-focused coping (both engagement and disengagement types) were less common in the impulsive suicide group. Emotion-focused engagement coping was more common in the impulsive suicide attempt group while emotion-focused disengagement coping was less common. Those with impulsive suicide attempts had recollected greater number of life stressors as compared to those with nonimpulsive suicide attempts (student's $t=2.820, P=0.005)$. The most common stressors in the impulsive attempt group included family conflict, financial issues, and marital conflict.

\section{Discussion}

Impulsive suicidal attempts comprised a substantial proportion of suicide attempts in a given period in the clinic. The rate of impulsive attempts in the present study (about $48 \%)$ is similar to that reported in certain studies ${ }^{[21,23,26]}$ but higher than the rate reported in others. ${ }^{[4,27]}$ Studies have used different operational definitions for classifying suicide attempts as impulsive. These have been based upon the intent criteria from Beck Suicide Intent Scale or the time duration between suicidal ideas and attempts as in the present study. The demographic characteristics between impulsive and nonimpulsive did not significantly differ, a finding which is similar to other studies ${ }^{[4,8,23,28]}$ though an earlier study did report an association between female gender and impulsive suicide. ${ }^{[28,29]}$

Our study did not find a significant difference in psychiatric diagnoses between impulsive and nonimpulsive suicide attempters. This is at variance with two earlier studies ${ }^{[8,30]}$ which reported a positive association between impulsive suicide and certain psychiatric disorders, particularly mood disorders, alcohol use disorder, and posttraumatic stress disorder. ${ }^{[8]}$ In contrast, other authors have reported lower levels of depression in impulsive suicide attempters. ${ }^{[21]}$ 
Table 2: Clinical characteristics of the impulsive and nonimpulsive suicide attempters

\begin{tabular}{|c|c|c|c|}
\hline & $\begin{array}{c}\text { Impulsive suicide } \\
\text { attempts }(n=151)(\%)\end{array}$ & $\begin{array}{l}\text { Non-impulsive suicide } \\
\text { attempts }(n=165)(\%)\end{array}$ & $\begin{array}{l}\chi^{2} / \text { Mann-Whitney U or } \\
\text { students' } t \text { (significance) }\end{array}$ \\
\hline \multicolumn{4}{|l|}{ Mode of the current attempt } \\
\hline Pesticides & $91(60.3)$ & $110(66.7)$ & $1.396(0.237)$ \\
\hline Natural plant products & $41(27.2)$ & $21(12.7)$ & $10.403(0.001)^{*}$ \\
\hline Physical methods & $1(0.7)$ & $12(7.3)$ & $8.734(0.003)^{\S, *}$ \\
\hline Prescription medicine overdose & $13(8.6)$ & $11(6.7)$ & $0.424(0.515)$ \\
\hline Attempt under intoxication & $19(12.6)$ & $24(14.5)$ & $0.258(0.611)$ \\
\hline \multicolumn{4}{|l|}{ Reason of current attempt } \\
\hline IPR issues with spouse & $30(19.9)$ & $42(25.5)$ & $1.399(0.237)$ \\
\hline IPR issues with others & $62(41.1)$ & $81(49.1)$ & $2.053(0.152)$ \\
\hline Financial & $9(6.0)$ & $18(10.9)$ & $2.471(0.116)$ \\
\hline Love related issues & $24(15.9)$ & $6(3.6)$ & $13.787(<0.001)^{*}$ \\
\hline Physical illness & $19(12.6)$ & $23(13.9)$ & $0.126(0.723)$ \\
\hline Preexisting psychiatric illness & $5(3.3)$ & $5(3)$ & $0.020(0.887)$ \\
\hline Exam related & $5(3.3)$ & $4(2.4)$ & $0.224(0.636)^{\S}$ \\
\hline Prior suicide attempt & $14(9.3)$ & $26(15.8)$ & $3.072(0.080)$ \\
\hline Prior family history of suicide & $25(16.6)$ & $25(15.2)$ & $0.117(0.733)$ \\
\hline Current alcohol use & $61(40.4)$ & $57(34.5)$ & $1.257(0.262)$ \\
\hline Current smoking & $39(25.8)$ & $34(20.6)$ & $1.371(0.242)$ \\
\hline Contact with any health professional in past 3 months prior to attempt & $37(24.5)$ & $24(14.5)$ & $8.392(0.004)^{*}$ \\
\hline Current psychiatric disorder & $66(43.7)$ & $64(38.8)$ & $0.788(0.375)$ \\
\hline Adjustment disorder & 53 & 55 & - \\
\hline Substance use disorder & 13 & 17 & - \\
\hline Mood disorder & 1 & 4 & - \\
\hline Others & 4 & 3 & - \\
\hline
\end{tabular}

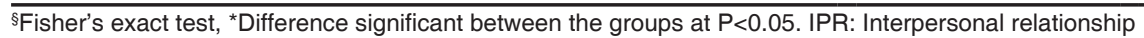

Table 3: Hopelessness, coping, and life stressors

\begin{tabular}{|c|c|c|c|}
\hline & $\begin{array}{l}\text { Impulsive suicide } \\
\text { attempters }(n=151)\end{array}$ & $\begin{array}{l}\text { Non-impulsive suicide } \\
\text { attempters }(n=165)\end{array}$ & $\begin{array}{l}\chi^{2} / \text { Mann-Whitney } U \text { or } \\
\text { students' } t \text { (significance) }\end{array}$ \\
\hline BHS score & $3.9( \pm 4.2)$ & $2.1( \pm 2.6)$ & $7680.5(<0.001)^{*}$ \\
\hline BHS score above cut-off (\%) & $16(11.0)$ & $5(3.3)$ & $6.855(0.009)^{*}$ \\
\hline \multicolumn{4}{|l|}{ CSI-SF subscale scores } \\
\hline Problem focused engagement & $11.3( \pm 4.2)$ & $12.2( \pm 3.7)$ & $2.034(0.043)^{*}$ \\
\hline Problem focused disengagement & $11.8( \pm 2.6)$ & $12.5( \pm 2.4)$ & $2.319(0.021)^{*}$ \\
\hline Emotion focused engagement & $10.6( \pm 2.9)$ & $10.0( \pm 2.6)$ & $2.048(0.041)^{*}$ \\
\hline Emotion focused disengagement & $10.5( \pm 2.2)$ & $11.2( \pm 2.3)$ & $2.518(0.012)^{*}$ \\
\hline Number of life stressors reported according to PSLES & $3.5( \pm 2.2)$ & $2.8( \pm 2.0)$ & $2.820(0.005)^{*}$ \\
\hline \multicolumn{4}{|l|}{ The most common life stressors on PSLES (\%) } \\
\hline Family conflict & $48(31.8)$ & $52(31.5)$ & $0.003(0.956)$ \\
\hline Financial loss or problems & $38(25.2)$ & $33(20.0)$ & $1.208(0.272)$ \\
\hline Marital conflict & $35(23.2)$ & $35(21.2)$ & $0.177(0.674)$ \\
\hline Excessive use of alcohol or drugs by a family member & $28(18.5)$ & $30(18.2)$ & $0.007(0.933)$ \\
\hline Major personal illness or injury & $29(19.2)$ & $28(17.0)$ & $0.296(0.586)$ \\
\hline Large loan & $27(17.9)$ & $26(15.8)$ & $0.255(0.614)$ \\
\hline Major purchase or construction of house & $19(12.6)$ & $15(9.1)$ & $1.001(0.317)$ \\
\hline Unfulfilled commitments & $10(6.6)$ & $22(13.3)$ & $3.901(0.048)^{*}$ \\
\hline Appearing for an examination or interview & $16(10.6)$ & $16(9.7)$ & $0.070(0.791)$ \\
\hline Self or family member unemployed & $16(10.6)$ & $15(9.1)$ & $0.202(0.653)$ \\
\hline Change in sleeping habits & $9(6.0)$ & $21(12.7)$ & $4.202(0.040)^{*}$ \\
\hline Illness of family member & $15(9.9)$ & $13(7.9)$ & $0.412(0.521)$ \\
\hline
\end{tabular}

${ }^{*}$ Difference significant between groups at $\mathrm{P}<0.05$. BHS: Beck hopelessness scale, CSI-SF: Coping strategies inventory short-form, PSLES: Presumptive stressful life events scale 
The methods of suicide attempt in the present study suggests that use of natural plant products to be more common in impulsive suicide attempters, while use of physical methods (hanging, stabbing etc.,) was less common. This probably reflects access to means of suicide and the time required to arrange for the same. Regionally, yellow oleander leaves (Oduvanthalai) are easily accessible means of suicide attempt, which was used more commonly by impulsive suicide attempters. Methods like hanging require some degree of preparation and were unlikely to be used by impulsive suicide attempters. Impulsive suicide attempts were unlikely to be more common under intoxication of alcohol. This was similar to results found in other studies who have found that use of alcohol was not associated with impulsive suicide attempts. ${ }^{[4,6]}$

Among the reasons of suicide attempt, love-related issues like break-ups were more commonly reported by the impulsive suicide attempters. It could be expected that impulsive suicide attempters would not have time to convey their intent to others. Conversely, nonimpulsive suicide attempters can be expected to closely conceal their plans for suicide in the preparation of executing the attempt. Congruent to our study, Simon et al. ${ }^{[4]}$ also found that impulsive suicide attempters were equally likely as nonimpulsive attempters to disclose their intentions to others.

The present study suggests that hopelessness was reported more commonly by impulsive suicide attempters. Though only a low proportion of suicide attempters had scores above cut-off on BHS, the impulsive suicide attempters had more percentage of individuals with hopelessness. Hopelessness has been shown to be dynamic in its nature and with this cross-sectional assessment may be difficult to draw conclusions. The overall relationship between hopelessness and impulsive suicide attempt is unclear at present with both positive $\mathrm{e}^{[4]}$ and negative ${ }^{[6]}$ associations being reported.

The present study suggests that the problem focused engagement was used less commonly by the impulsive suicide attempters. Emotion-focused engagement was used more commonly by the impulsive suicide attempters which includes elements like hoping the problem will take care of itself or try to put problem out of mind. This suggests that impulsive suicide attempters use less pragmatic means of defusing the problems, and react in an emotional manner. Previous studies have suggested that avoidance coping is more common in suicide attempters in general. ${ }^{[28,30]}$ This study is, however, probably the first to find an association of impulsivity with their coping styles among suicide attempters.
It was seen that impulsive suicide attempters reported a greater number of life stressors, though the profile of the stressors were similar. Impulsive suicide attempters might be more predisposed to difficult life circumstances and interpersonal problems. On the other hand, certain specific types of stress, such as loss, may be more associated with planned suicide attempts. ${ }^{[30]}$ The cumulative effect of multiple stressors might lead an individual to the extreme step of a suicide attempt. Other studies have found high rates of stressful life events using PSLES among suicide attempters, ${ }^{[31,32]}$ but ours is the first study comparing impulsive and nonimpulsive suicide attempters using PSLES.

The findings of the study are subject to certain limitations which should be considered while drawing interpretations. This includes retrospective data collection from a CIC, structured instruments not being used for diagnosing psychiatric disorders including personality disorders, a possibility of referral bias, and ascertainment of impulsive suicide being based upon person's self-report. Selected variables of interest were studied while many other variables like depressive symptoms and trait impulsivity were not systematically assessed as a part of the current study. Moreover, availability of validated scales in the local language would enhance the research quality in the future.

To conclude, impulsive suicide attempts are fairly common in the sample of suicide attempters who seek medical treatment. This group of patients is similar to nonimpulsive attempters in terms of demographic features but differs on certain clinical characteristics such as the mode and reason of attempt, hopelessness, type of coping, and number of stressors. Identification of impulsive suicide attempts is likely to help streamline the treatment of individuals presenting to the treatment settings. There is a need for a common definition of impulsive suicide attempts, which would help establish the validity of this sub-group. Further studies should focus upon examining the relationship of impulsive suicide attempts with demonstrable trait impulsivity, a relationship which appears to be complex and indirect. ${ }^{[5]}$ This would lead to the development of appropriate psychological interventions which would focus on problem-solving strategies to deal with life stressors among those with impulsive suicide attempts.

\section{References}

1. Mann JJ, Waternaux C, Haas GL, Malone KM. Toward a clinical model of suicidal behavior in psychiatric patients. Am J Psychiatry 1999;156:181-9.

2. Knox KL, Conwell Y, Caine ED. If suicide is a public health problem, what are we doing to prevent it? Am J Public Health 2004;94:37-45. 
3. Brown MZ, Comtois KA, Linehan MM. Reasons for suicide attempts and nonsuicidal self-injury in women with borderline personality disorder. J Abnorm Psychol 2002;111:198-202.

4. Simon OR, Swann AC, Powell KE, Potter LB, Kresnow MJ, O’Carroll PW. Characteristics of impulsive suicide attempts and attempters. Suicide Life Threat Behav 2001;32:49-59.

5. Baca-García E, Diaz-Sastre C, Basurte E, Prieto R, Ceverino A, Saiz-Ruiz J, et al. A prospective study of the paradoxical relationship between impulsivity and lethality of suicide attempts. J Clin Psychiatry 2001;62:560-4.

6. Spokas M, Wenzel A, Brown GK, Beck AT. Characteristics of individuals who make impulsive suicide attempts. J Affect Disord 2012;136:1121-5.

7. Conner KR. A call for research on planned vs. unplanned suicidal behavior. Suicide Life Threat Behav 2004;34:89-98.

8. Jeon HJ, Lee JY, Lee YM, Hong JP, Won SH, Cho SJ, et al. Unplanned versus planned suicide attempters, precipitants, methods, and an association with mental disorders in a Korea-based community sample. J Affect Disord 2010;127:274-80.

9. Mathew A, Nanoo S. Psychosocial stressors and patterns of coping in adolescent suicide attempters. Indian J Psychol Med 2013;35:39-46.

10. Rickelman BL, Houfek JF. Toward an interactional model of suicidal behaviors: Cognitive rigidity, attributional style, stress, hopelessness, and depression. Arch Psychiatr Nurs 1995;9:158-68.

11. Brent D. In search of endophenotypes for suicidal behavior. Am J Psychiatry 2009;166:1087-9.

12. Nock MK, Hwang I, Sampson N, Kessler RC, Angermeyer M, Beautrais A, et al. Cross-national analysis of the associations among mental disorders and suicidal behavior: Findings from the WHO World Mental Health Surveys. PLoS Med 2009;6:e1000123.

13. Vijaykumar L. Suicide and its prevention: The urgent need in India. Indian J Psychiatry 2007;49:81-4.

14. Bastia BK, Kar N. A psychological autopsy study of suicidal hanging from Cuttack, India: Focus on stressful life situations. Arch Suicide Res 2009;13:100-4.

15. Manoranjitham SD, Rajkumar AP, Thangadurai P, Prasad J, Jayakaran R, Jacob KS. Risk factors for suicide in rural south India. Br J Psychiatry 2010;196:26-30

16. Silverman MM, Berman AL, Sanddal ND, O'carroll PW, Joiner TE. Rebuilding the tower of Babel: A revised nomenclature for the study of suicide and suicidal behaviors. Part 2: Suicide-related ideations, communications, and behaviors. Suicide Life Threat Behav 2007;37:264-77.

17. Beck AT, Weissman A, Lester D, Trexler L. The measurement of pessimism: The hopelessness scale. J Consult Clin Psychol 1974;42:861-5.

18. Addison CC, Campbell-Jenkins BW, Sarpong DF, Kibler J, Singh M, Dubbert P, et al. Psychometric evaluation of a Coping Strategies Inventory Short-Form (CSI-SF) in the Jackson Heart Study cohort. Int J Environ Res Public Health 2007;4:289-95.
19. Singh G, Kaur D, Kaur H. Presumptive stressful life events scale (PSLES) - A new stressful life events scale for use in India. Indian J Psychiatry 1984;26:107-14.

20. WHO. The ICD-10 Classification of Mental and Behavioural Disorders. Clinical Descriptions and Diagnostic Guidelines. Geneva: World Health Organization; 1992

21. Williams CL, Davidson JA, Montgomery I. Impulsive suicidal behavior J Clin Psychol 1980;36:90-4.

22. Wojnar M, Ilgen MA, Czyz E, Strobbe S, Klimkiewicz A, Jakubczyk A, et al. Impulsive and non-impulsive suicide attempts in patients treated for alcohol dependence. J Affect Disord 2009;115:131-9.

23. Wei S, Liu L, Bi B, Li H, Hou J, Chen W, et al. Comparison of impulsive and nonimpulsive suicide attempt patients treated in the emergency departments of four general hospitals in Shenyang, China. Gen Hosp Psychiatry 2013;35:186-91.

24. Tobin DL, Holroyd KA, Reynolds RV, Wigal JK. The hierarchical factor structure of the Coping Strategies Inventory. Cogn Ther Res1989;13:343-61.

25. Holmes TH, Rahe RH. The social readjustment rating scale. J Psychosom Res 1967;11:213-8.

26. Deisenhammer EA, Ing CM, Strauss R, Kemmler G, Hinterhuber H, Weiss EM. The duration of the suicidal process: How much time is left for intervention between consideration and accomplishment of a suicide attempt? J Clin Psychiatry 2009;70:19-24.

27. Wyder M, De Leo D. Behind impulsive suicide attempts: Indications from a community study. J Affect Disord 2007;104:167-73.

28. Curry JF, Miller Y, Waugh S, Anderson WB. Coping responses in depressed, socially maladjusted, and suicidal adolescents. Psychol Rep 1992;71:80-2.

29. Weyrauch KF, Roy-Byrne P, Katon W, Wilson L. Stressful life events and impulsiveness in failed suicide. Suicide Life Threat Behav 2001;31:311-9

30. Wilson KG, Stelzer J, Bergman JN, Kral MJ, Inayatullah M, Elliott CA. Problem solving, stress, and coping in adolescent suicide attempts. Suicide Life Threat Behav 1995;25:241-52.

31. Srivastava MK, Sahoo RN, Ghotekar LH, Dutta S, Danabalan M, Dutta TK, et al. Risk factors associated with attempted suicide: A case control study. Indian J Psychiatry 2004;46:33-8.

32. Sudhir Kumar CT, Mohan R, Ranjith G, Chandrasekaran R. Gender differences in medically serious suicide attempts: A study from south India. Psychiatry Res 2006;144:79-86.

How to cite this article: Kattimani S, Sarkar S, Rajkumar RP, Menon V. Stressful life events, hopelessness, and coping strategies among impulsive suicide attempters. J Neurosci Rural Pract 2015;6:171-6.

Source of Support: Nil. Conflict of Interest: None declared.

\section{Author Help: Reference checking facility}

The manuscript system (www.journalonweb.com) allows the authors to check and verify the accuracy and style of references. The tool checks the references with PubMed as per a predefined style. Authors are encouraged to use this facility, before submitting articles to the journal.

- The style as well as bibliographic elements should be $100 \%$ accurate, to help get the references verified from the system. Even a single spelling error or addition of issue number/month of publication will lead to an error when verifying the reference.

- Example of a correct style Sheahan P, O'leary G, Lee G, Fitzgibbon J. Cystic cervical metastases: Incidence and diagnosis using fine needle aspiration biopsy. Otolaryngol Head Neck Surg 2002;127:294-8.

- Only the references from journals indexed in PubMed will be checked.

- Enter each reference in new line, without a serial number.

- Add up to a maximum of 15 references at a time.

- If the reference is correct for its bibliographic elements and punctuations, it will be shown as CORRECT and a link to the correct article in PubMed will be given.

- If any of the bibliographic elements are missing, incorrect or extra (such as issue number), it will be shown as INCORRECT and link to possible articles in PubMed will be given. 